University of Nebraska - Lincoln

DigitalCommons@University of Nebraska - Lincoln

Office of Research and Economic

Development--Publications

Research and Economic Development, Office of

2011

\title{
Macrocyclic fragrance materials-A screening-level environmental assessment using chemical categorization
}

\author{
Daniel Salvito \\ Research Institute for Fragrance Materials, Woodcliff Lake, NJ, dsalvito@rifm.org \\ Aurelia Lapczynski \\ Research Institute for Fragrance Materials, Woodcliff Lake, NJ \\ Christen Sachse-Vasquez \\ Takasago International Corporation, Rockleigh, NJ \\ Colin Mclntosh \\ Firmenich, Inc. Princeton, NJ \\ Peter Calow \\ University of Nebraska-Lincoln, pcalow2@unl.edu \\ See next page for additional authors
}

Follow this and additional works at: https://digitalcommons.unl.edu/researchecondev

Part of the Higher Education Administration Commons

Salvito, Daniel; Lapczynski, Aurelia; Sachse-Vasquez, Christen; McIntosh, Colin; Calow, Peter; Greim, Helmut; and Escher, Beate, "Macrocyclic fragrance materials-A screening-level environmental assessment using chemical categorization" (2011). Office of Research and Economic Development-Publications. 39.

https://digitalcommons.unl.edu/researchecondev/39

This Article is brought to you for free and open access by the Research and Economic Development, Office of at DigitalCommons@University of Nebraska - Lincoln. It has been accepted for inclusion in Office of Research and Economic Development--Publications by an authorized administrator of DigitalCommons@University of Nebraska Lincoln. 


\section{Authors}

Daniel Salvito, Aurelia Lapczynski, Christen Sachse-Vasquez, Colin Mclntosh, Peter Calow, Helmut Greim, and Beate Escher 


\title{
Macrocyclic fragrance materials - A screening-level environmental assessment using chemical categorization
}

\author{
Daniel Salvito, ${ }_{1}^{1}$ Aurelia Lapczynski, ${ }^{1}$ Christen Sachse-Vasquez, ${ }^{2}$ Colin McIntosh, ${ }^{3}$ \\ Peter Calow, ${ }^{4}$ Helmut Greim, ${ }^{5}$ Beate Escher ${ }^{6}$
}

\author{
1. Research Institute for Fragrance Materials, 50 Tice Boulevard, Woodcliff Lake, NJ 07677, USA \\ 2. Takasago International Corporation, Rockleigh, NJ, USA \\ 3. Firmenich, Inc. Princeton, NJ, USA \\ 4. Roskilde University, Department of Environmental, Social \& Spatial Change, Roskilde, Denmark \\ 5. Technical University of Munich, Institute for Toxicology \& Environmental Hygiene, Freising-Weihenstephan, Germany \\ 6. University of Queensland, National Research Centre for Environment Toxicology (EnTox), Coopers Plains, Australia \\ Corresponding author - D. Salvito, dsalvito@rifm.org
}

\begin{abstract}
A screening-level aquatic environmental risk assessment for macrocyclic fragrance materials using a "group approach" is presented using data for 30 macrocyclic fragrance ingredients. In this group approach, conservative estimates of environmental exposure and ecotoxicological effects thresholds for compounds within two subgroups (15 macrocyclic ketones and 15 macrocyclic lactones/lactides) were used to estimate the aquatic ecological risk potential for these subgroups. It is reasonable to separate these fragrance materials into the two subgroups based on the likely metabolic pathway required for biodegradation and on expected different ecotoxicological modes of action. The current volumes of use for the macrocyclic ketones in both Europe and North America ranges from $<1$ (low kg quantities) to no greater than 50 metric tons in either region and for macrocyclic lactones/lactides the volume of use range for both regions is $<1$ to no greater than 1000 metric tons in any one region. Based on these regional tonnages, biodegradability of these two subgroups of materials, and minimal in stream dilution (3:1), the conservatively predicted exposure concentrations for macrocyclic ketones would range from $<0.01$ to 0.05 $\mu \mathrm{g} / \mathrm{L}$ in Europe and from $<0.01$ to $0.03 \mu \mathrm{g} / \mathrm{L}$ in North America. For macrocyclic lactones/lactides, the concentration within the mixing zone would range from $<0.01$ to $0.7 \mu \mathrm{g} / \mathrm{L}$ in Europe and from $<0.01$ to $1.0 \mu \mathrm{g} / \mathrm{L}$ in North America. The PNECs derived for the macrocyclic ketones is $0.22 \mu \mathrm{g} / \mathrm{L}$ and for macrocyclic lactones/lactides is $2.7 \mu \mathrm{g} / \mathrm{L}$. The results of this screening-level aquatic ecological risk assessment indicate that at their current tonnage, often referred to as volumes of use, macrocyclic fragrance materials in Europe and North America, pose a negligible risk to aquatic biota; with no PEC/PNEC ratio exceeding 1 for any material in any subgroup.
\end{abstract}

Keywords: risk assessment, chemical categorization, fragrance ingredients

\section{Introduction}

The Research Institute for Fragrance Materials (RIFM) “Framework for prioritizing fragrance materials for aquatic risk assessment" (termed "Environmental Framework" hereafter) was developed to screen a large database of organic compounds used as fragrance ingredients to assess their potential environmental risk and set priorities for further risk assessment, as necessary (Salvito et al., 2002). RIFM has been using a group or chemical categories approach based on structure-activity relationships for the assessment of human health safety (Bickers et al., 2003). Presented here is the first application of this group approach for the aquatic risk assessment of structurally related groups of fragrance ingredients using the example of macrocyclic fragrance ingredients. Macrocyclic fra- grance materials are important fragrance ingredients and are widely used in cosmetics, detergents, fabric softeners, cleaning products and other household products. This approach is based on the hypothesis that if chemicals are structurally related, they behave similarly in the aquatic environment. In the group approach, available environmental fate and effects values for individual compounds within the group are used to conservatively estimate the potential for aquatic ecological risks for the entire structurally related group. The fragrance materials in the macrocyclic ketone group and the macrocyclic lactone and lactide group have been reviewed in separate human health group summaries (Belsito et al., in press a, in press b). These group summaries contain references to the Fragrance Material Reviews that provide the human health data for each of the individual materials in the group. 


\subsection{Principles of chemical categorization}

Chemical categorization, also referred to as "chemical grouping", is a method of identifying analogs for chemicals of interest and enabling the extrapolation of a specific endpoint(s) of data-poor chemicals from data rich chemicals. Analogs can be read-across one chemical to one chemical, one to many, or many to many. The OECD has established guidance on the formation of categories and guidance has also been prepared in preparation for REACH by a REACH Implementation Project (OECD, 2005).

\subsection{General guidelines}

The group approach as applied here followed the guidance provided by the OECD (OECD, 2005) for the formation of chemical categories. This guidance could be applied to both human health and environmental endpoints. The principles are:

1. Identify chemical category and assign its members.

2. Gather published and unpublished data for each category member.

3. Evaluate available data for adequacy in assessing the domain hypothesis.

4. Construct a matrix of data availability.

5. Perform an internal assessment of the category.

6. Prepare a category test plan.

7. Conduct the necessary testing.

8. Perform an external assessment of the category and fill data gaps.

The key steps for establishing a hypothesis and determining the validity of the hypothesis are steps 1 and 5; supported by the data gathering and review steps ( 2 through 4$)$. Step 1 identifies the potential domain of the category and establishes the hypothesis built upon said domain. In a general sense a group of organic chemicals containing similar functional groups and covering a specified physical-chemical property range, potentially linked metabolically, should have endpoints that are predictive based on the findings of other members within the category.

The purpose of Step 5 is to test the hypothesis formulated in Step 1; i.e. trying to refute its premise that the group selected is a reasonable one for read-across. This is done using the existing information and, assessing in parallel persistence $(P)$, bioaccumulation $(B)$ and toxicity $(T)$ criteria. This part of the analysis will involve a more careful consideration of structure, QSAR and metabolic pathways than in Step 1. For example, the endpoints should support the metabolic pathway hypothesis and/or fit a well-validated QSAR. The possible outcomes of Step 5 are:

- Reject the entire category (should occur rarely).

- Reject some members based on sound scientific reasoning-poor fit with remaining members (expected outcome).

- Develop candidate subcategories (note that the outcome here may be hierarchal; e.g. a "P" group with 2 different "BT" subgroups).

Subcategory size should be the largest possible group of chemicals that shows common features (i.e., supports the domain hypothesis). However, the category itself may be the best fit for all endpoints (i.e., no need for subcategorization).

At this point there is likely to be a need for the collection of more data (Steps 6-8) for at least two purposes. To further test the hypothesis that the category is a sound one and to fill important data gaps.

The following points have to be considered during the process:

- Categorization and its associated hypothesis testing is a weight of evidence approach. There are likely to be outliers that should fit the category but do not. To the extent possible, these outliers should be explained; e.g., $a, \beta$ unsaturation with respect to carbonyl groups present is a different category that is not part of the general group of ketones.

- Categorization is an approach in which both the favorable and unfavorable aspects of available data are applied equally.

- The use of chemical categories does not preclude minimal testing strategies (i.e., minimally, physical-chemical properties have to be measured or estimated and ready biodegradation studies will need to be performed).

- Subcategories for different endpoints may not match between endpoints relevant for human health and environmental endpoints (or even within); e.g., a skin sensitization subcategory may not contain all the same members as a persistence subcategory.

- Consideration of consistency between categories is important as well. There will be chemicals that will reside in more than one category. The development of the domain parameters and the category hypothesis should be applicable for the chemical in both (or more) categories. Furthermore, the conclusions for the appropriate subcategories, in this case where a chemical would reside in two distinct groups, should be consistent (e.g., the chemical cannot be bioaccumulative in one subcategory and not bioaccumulative in another).

\subsection{Specific guidelines for endpoint assessment in categorization}

While the principles outlined above provide guidance for the building and assessment of chemical categories in a broad sense, below are additional guidance for evaluating specific endpoints for environmental exposure (persistence and bioaccumulation data) and aquatic effects.

\subsubsection{Persistence}

If no experimental data are available the following computational models can serve as assessment tools:

a.) CATABOL - for commonality of metabolic pathways;

b.) METEOR - for mammalian metabolism; may be useful for $\mathrm{P}$ assessment and for fish metabolism;

c.) University of Minnesota Biocatalysis/Biodegradation Database - for degradation reaction pathways.

The following questions need to be addressed:

1. Structural assessment: Does the same path exist for the chemicals in the groups for initial primary degradation (same sites of attack)?

2. Are there breaks in the available dataset between readily biodegradable materials, inherently biodegradable materials, and non-biodegradable materials that are structurally defined?

3. Structural assessment: Is the pathway for biodegradation likely to go to completion (mineralization) or are there structural biophobes that are likely to inhibit this process?

4. Do potential metabolites (i.e., breakdown products), of the chemicals that do not completely metabolize have $\mathrm{B}$ or $\mathrm{T}$ properties?

5. What is the expectation of performance in a ready test (should be able to predict \% biodegradation)?

6. If no ready biodegradation is predicted:

a.) Is the material toxic under test conditions?

b.) Do organisms have difficulty growing on the chemical to permit primary degradation (i.e., co-metabolism)?

c.) Is the material bioavailable?

d.) What is expected in aerobic versus anaerobic tests? 


\subsubsection{Bioaccumulation}

In a first step, the materials are grouped in classes with known metabolic activity versus non- or poorly metabolized materials.

- For non (poorly)-metabolizable chemicals separations between non-B/B/vB is based on the hydrophobicity indicator octanol-water partition coefficient $K_{\mathrm{OW}}$;

- For categories with more than one metabolic pathway, separate by pathway.

\subsubsection{Ecotoxicity}

The classes are separated via mode of action (MOA) classification. For fragrance materials this separation is largely between narcosis (both Type I and II) and reactive toxicants (e.g., aldehydes). These mode-of-action classifications were originally proposed by Verhaar et al. (1992) and have had wide application in ecotoxicology. MOA I and II (nonpolar and polar narcosis) chemicals can more than likely be grouped together as they have a common underlying mechanism (Vaes et al., 1998). The difference is not very significant. ECETOC developed a more robust method for determining MOA (Thomas et al., 2008) beyond the use of the structural alerts of Verhaar et al. (1992).

This weight of evidence approach, in whole or in part, may prove useful in categorizing for ecotoxic endpoints.

\section{Materials and methods}

\subsection{Domain definition: macrocyclic fragrance ingredients}

2.1.1. Structural similarity and physical-chemical properties (identify chemical category and assign its members)

These macrocyclic fragrance materials are important fragrance ingredients and are widely used in cosmetics, detergents, fabric softeners, cleaning products and other household products. The groups of macrocyclic fragrance ingredients identified for this study consist of two structural classes (i.e., subcategories), macrocyclic ketones and macrocyclic lactones/lactides. The materials specifically identified in this study are a complete list of macrocyclic fragrance materials, as of this publication, used in commerce and found in the RIFM Database. The process de- scribed above for defining and assessing chemical categories was adhered to. Both of these classes are represented by a large carbon ring (typically 14-17 carbons, Figure 1). Unsaturation may also be present on the carbon ring. From the domain assessment that follows and a review of the available data, the presence or absence of unsaturation in the ring does not appear to necessitate further differentiation of these subgroups (i.e., there is no apparent effect on biodegradation or toxicity for these chemicals). The macrocyclic ketones contain only a single carbonyl functional group on the ring. The macrocyclic lactones/lactides contains one or two cyclic ester functional groups and, in the case of the lactones may also contain an additional ring oxygen or carbonyl group. Thirty different macrocyclic compounds were included in this group assessment, 15 lactones/lactides and 15 ketones. Their physical-chemical properties are presented in Table 1. Measured data are provided where available. When measured values were not available, physical-chemical property estimates were calculated using the USEPA's EPI Suite models (version 4.0).

\subsubsection{Microbial metabolism}

2.1.2.1. Gather published and unpublished data for each category member; evaluate available data for adequacy; construct a matrix of data availabil$i t y$. In addition to the structural differences between the two chemical classes, the macrocyclic ketones would have to undergo oxidation to a lactone during biodegradation and then further degrade via ester hydrolysis. The materials in the lactone/lactide subgroup would, therefore, degrade directly via ester hydrolysis. This microbial pathway was identified using the University of Minnesota Biocatalysis/Biodegradation Database (Gao et al., 2010) and shows, for cyclohexanone, BaeyerVilliger oxidation of a cyclic ketone to a cyclic lactone (neutral under aerobic conditions) followed by the lactone forming the hydroxy carboxylate (likely under aerobic conditions). A representative reaction pathway is shown in Figure 2.

2.1.2.2. Perform an internal assessment of the category. The two principally different pathways are supported by the difference in biodegradation predicted by BIOWIN for the two classes (i.e., predict "not readily biodegradable" for the ketones and "readily biodegradable" for the lactones/lactides). This difference in prediction by the BIOWIN model is likely due to the necessity of an initial oxidation step for the ketones as noted above. Standardized experimental studies of biodegradation may not necessarily provide the data needed to demonstrate this difference. Thus, based on a weight of evidence approach, the biodegradation data for both groups of materials indicates that these compounds are readily biodegradable. However, the known difference in metabolism does support the distinction between the two subclasses (Table 2).

\begin{tabular}{|l|l|l|}
\hline Subgroup & Ketones \\
Structure & \\
& \\
\hline Number of materials & 15 & Lactones/Lactides \\
\hline Verhaar Mode of Action & Non-Polar Narcosis & \begin{tabular}{l} 
Polar Narcosis \\
\hline Biodegradation Class
\end{tabular} \\
\hline Ring Size & Inherent to Readily & $\begin{array}{l}\text { C14 to C16 } \\
\text { and methyl side chain. Lactides } \\
\text { contain additional carbonyl group } \\
\text { and ring oxygen (i.e, diester) }\end{array}$ \\
\hline Notes & $\begin{array}{l}\text { May contain unsaturation in } \\
\text { ring and methyl side chain }\end{array}$ & \\
\hline
\end{tabular}

Figure 1. Domain definition. 


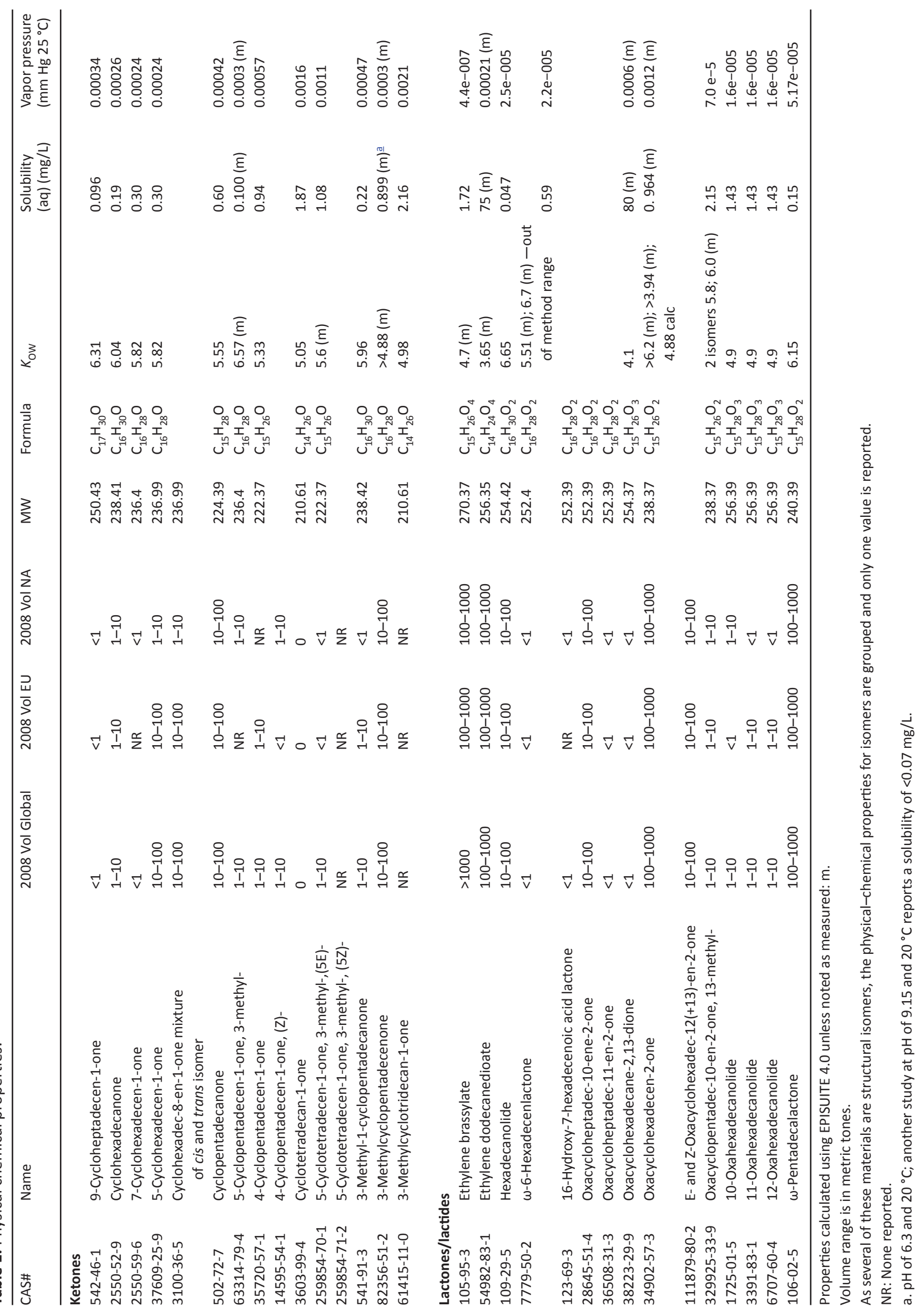




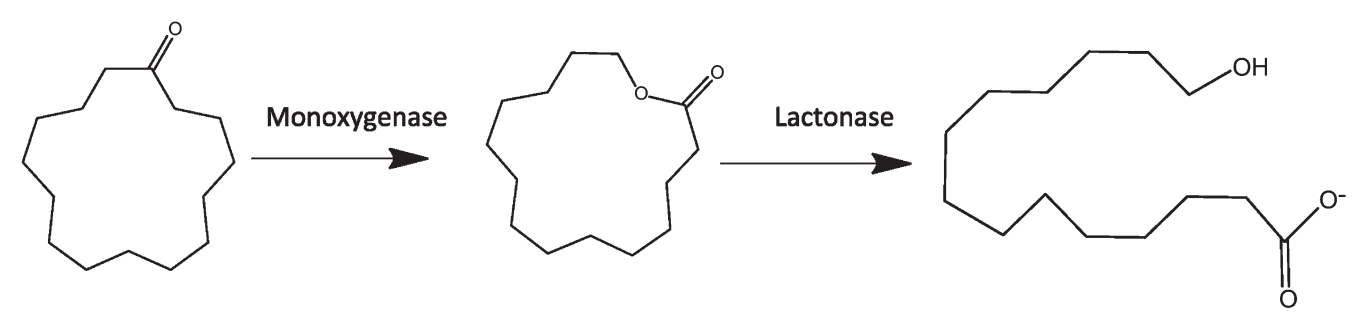

Figure 2. Representative reaction pathway for microbial metabolism of macrocyclic ketones and lactones.

\subsubsection{Ecotoxicological mode of action}

2.1.3.1. Gather published and unpublished data for each category member, evaluate available data for adequacy, construct a matrix of data availability. The aquatic toxicity data is summarized in Table 3.

Note: References noted in Table 2 and Table 3 represent a significant number of unpublished studies from the RIFM Database. The complete citations for these studies can be found in the Supplemental Information provided for this paper.

2.1.3.2. Perform an internal assessment of the category. According to Verhaar et al.'s (1992) rules for identifying ecotoxicological mode of action for organic compounds, the ketones would likely act as non-polar narcotics (Type I) and the lactones/lactides as polar narcotics (Type II). As noted earlier, as there is little to differentiate between these two modes of action, the measured aquatic toxicity varies little between the two subcategories. It can be noted, in support of this distinction, that the USEPA's QSAR model ECOSAR differentiates between the two classes of compounds as well. ECOSAR applies the neutral organic QSAR to the ketones and the ester QSAR to the lactones/lactides. Furthermore, comparison between the output of this QSAR and measured toxicity values is not necessarily confirmatory of correct classification of a chemical category. These QSARs both under and over predict toxicity compared with experimental results.

\subsubsection{Conclusion on chemical categories.}

As noted in Section 2.1.2, the measured experimental data for these two subgroups, are likely not sensitive enough to differentiate between the additional oxidation step needed for biodegradation or for differences between Type I and Type II narcosis in aquatic toxicity. However, following the Guidelines for categorization, the structural differences, microbial pathway for degradation, and ecotoxicological modes of action support the hypothesis that the macrocyclic fragrance materials are separable into two subcategories: ketones and lactoines/lactides (Figure $3)$. As this is an exercise in hypothesis testing, the data, in and of themselves, do not refute this hypothesis.

\subsection{Screening level risk assessment for the aquatic compartment}

\subsubsection{Problem formulation}

A screening-level risk assessment was performed using the RIFM Environmental Framework (Salvito et al., 2002). This framework includes problem formulation, evaluation of exposure (via a conservative predicted environmental concentration based on each individual material's continental tonnage) and ecotoxicological effect (via a predicted no effect concentration based on the lowest aquatic toxicity endpoint measured for any one material within a subgroup, but applied to the whole subgroup) and risk characterization. The assessment was performed for each group using data from all compounds in the group.

\subsubsection{Analysis - characterization of exposure: PEC}

The primary pathway by which fragrance materials can enter the environment during and after consumer use is as wastewater washed down drains (Salvito et al., 2002). A portion of the fragrance materials may volatilize to the atmosphere. The amount depends upon the type of consumer product the fragrance material is used in and the volatility of the fragrance compound. Another fraction will leave the household in the wastewater. Most wastewater is discharged to sewers that connect to wastewater treatment plants (WWTPs), and thus considering the total volume of use of the fragrance materials discharged to the wastewater is an appropriately conservative approach for a screening level risk assessment as described in the Framework (Salvito et al., 2002) and is also consistent with the ERA guidelines for pharmaceuticals (EMEA, 2006).

A typical WWTP includes primary treatment to remove solids and secondary treatment to remove dissolved and suspended organic matter. The most common type of secondary treatment is activated sludge. Removal of fragrance materials can involve sorption to sewage solids in primary and secondary treatment, biodegradation or biotransformation mainly during secondary treatment, and removal by clarification in the final clarifier before discharge to the aquatic environment. During conveyance in the sewer and treatment, some material can volatilize to the atmosphere. In addition, materials can be biodegraded, biotransformed, and sorbed to the sludge within the sewer. Materials removed by sorption to the sludge in the WWTP may be incinerated, landfilled, or amended to soil. Material not removed in the WWTP is discharged to surface waters, where biotransformation and biodegradation can continue. In the surface waters, materials may sorb to suspended solids and be transferred to the sediments.

Exposure is expressed as a PEC in the water column of the mixing zone, where WWTP effluent is diluted with surface water (e.g., stream or river). This concentration is determined by fragrance usage volume, removal during WWTP treatment, and dilution in the mixing zone (Salvito et al., 2002). This approach makes the following assumptions: the entire fragrance usage volume in a region is discharged via sewers to WWTPs; usage is evenly distributed across the population of a region; no losses occur during consumer use or conveyance in the sewer as a result of volatilization or other processes; no losses occur as a result of biodegradation, biotransformation, or abiotic chemical processes; and effluents are minimally diluted (3:1) in the mixing zone. As noted in Salvito et al. (2002) a 3:1 dilution is a conservative dilution estimate especially relative to the 10:1 dilution recommended in the technical guidance in Europe for localscale exposure calculations (ECHA, 2008a). The assumptions used in estimating operational aspects of wastewater treatment are that wastewater undergoes primary and secondary (activated sludge) treatment, removal during sewage treatment occurs only as a result of sorption, removal of solids during primary treatment is only $50 \%$ (many plants exhibit better efficiency), the level of suspended solids in the aeration vessel of the activated sludge system is $2500 \mathrm{mg} / \mathrm{L}$ (for many plants this value is closer to $3500 \mathrm{mg} / \mathrm{L}$ ), and the level of solids in final effluent is $20 \mathrm{mg} / \mathrm{L}$ (many plants have much lower solids levels in their effluents). This assessment depends on three input variables: regional usage volume (metric tons/ year), octanol-water partitioning coefficient $\left(K_{\mathrm{OW}}\right)$, and molecular weight. The model parameters and the conservative nature of this approach have been discussed elsewhere (Salvito et al., 2002). Macrocyclic fragrance materials have estimated $\log K_{\mathrm{OW}}$ values ranging from about 4.2 to about 6.7. Molecular weights generally are around $250 \mathrm{~g} / \mathrm{mol}$ (Table 1). Population differences, per capita water usage, and influent solid levels are the variants between scenarios for European and North American screening level exposure assessments (Salvito et al., 2002).

2.2.2.1. Calculation of the PEC. The PECs for all materials were estimated individually using the model described in the RIFM Environmental Framework (Salvito et al., 2002) for the European and North American scenarios. For macrocyclic fragrance materials, the PEC was estimated based on the reported volume of use (IFRA, 2008) in Europe and North America, the individual material's $\log K_{\mathrm{OW}}$ value, and a 3:1 dilution ratio to estimate exposure in the receiving stream. As the screening level assessment outlined in Salvito et al. (2002) is able to incorporate measured biodegradation data when available, as is the case for both macrocyclic fragrance ingredient subgroups, this rate $(1 / \mathrm{h})$ was included in the analysis (Salvito et al., 2002).

\subsubsection{Analysis - characterization of ecological effects: PNEC}

The potential toxic effects of a fragrance material in the aquatic environment were expressed in terms of a PNEC. All measured acute and chronic toxicity data available for each subgroup of compounds were evaluated and the lowest chronic no observed effect concentration (NOEC) for the subgroup was identified, based on measured concentrations. As data are not available for each compound in the particular subgroup, this NOEC was applied to all compounds within the subgroup to calculate risk quotients. This is consistent with using a "group approach". All of the toxicity tests were performed using Organization for Economic Cooperation and Development (OECD) methods (OECD, 2006a) or similar methodologies and are noted in Table 3. The PNEC was estimated by dividing the lowest chronic NOEC by an assessment factor selected using European Union guidelines (ECHA, 2008b) and the RIFM Environmental Framework (Salvito et al., 2002).

2.2.3.1. Risk characterization. Potential risk to the aquatic environment for each subgroup was estimated from the ratio of the PEC to PNEC (PEC) 


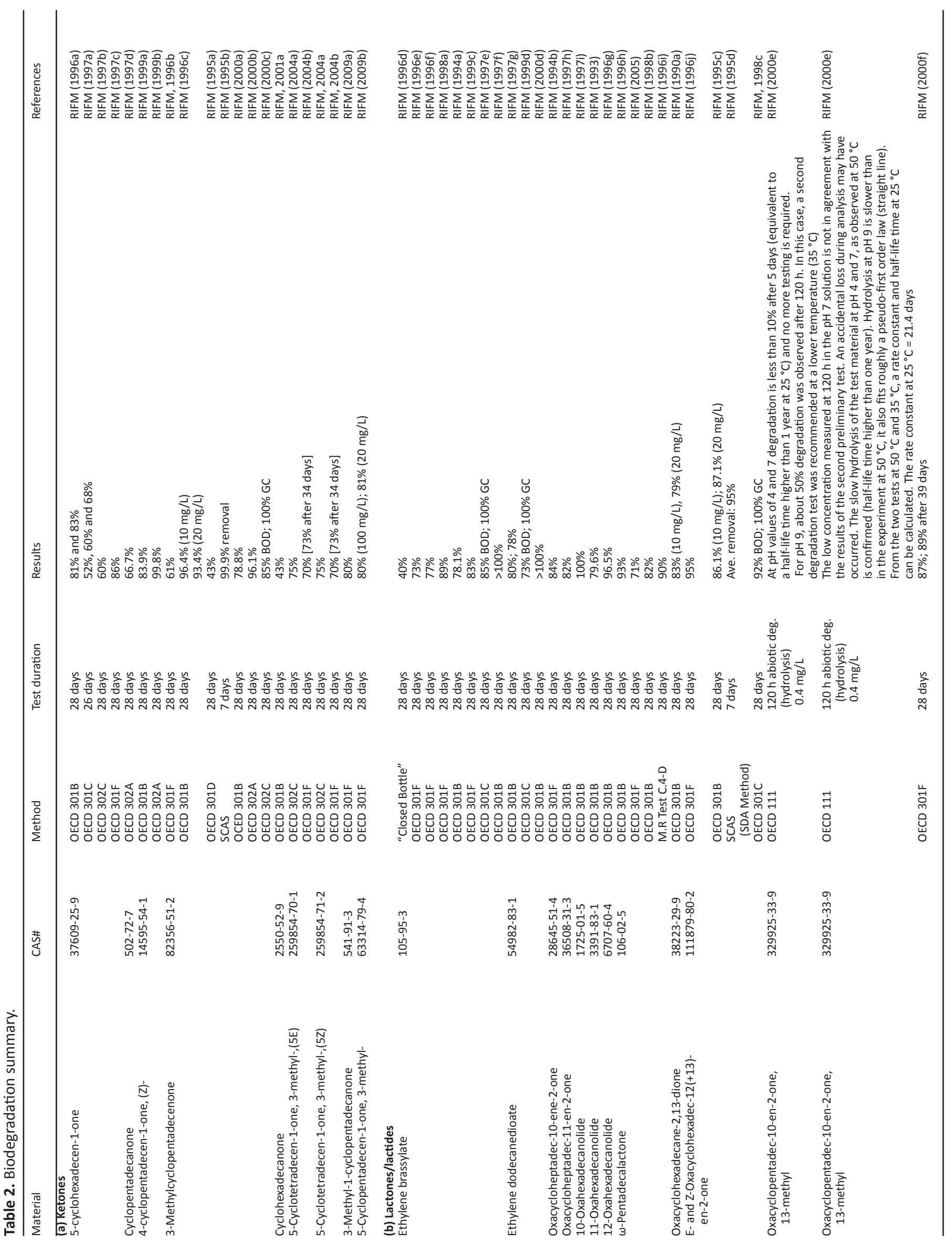




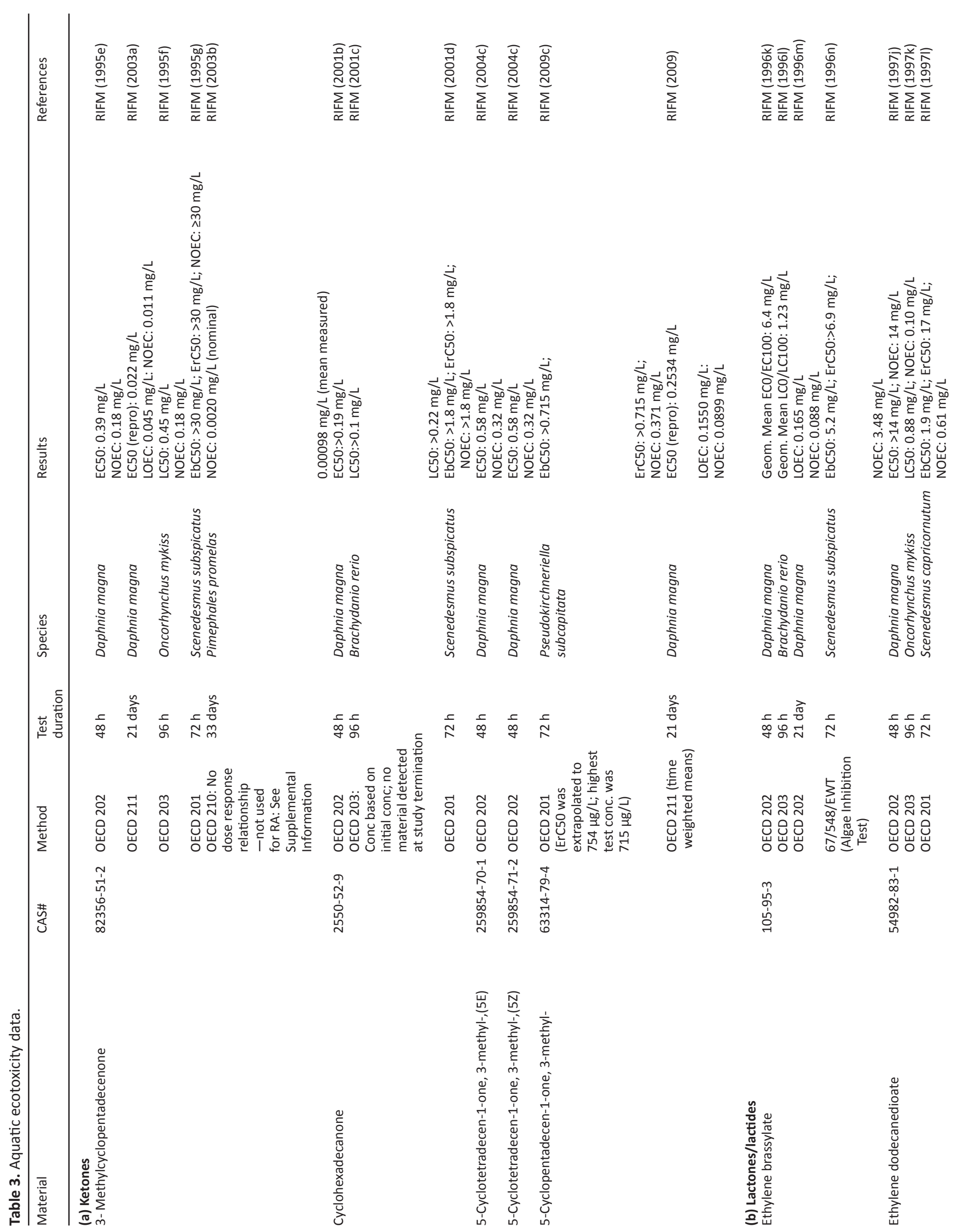




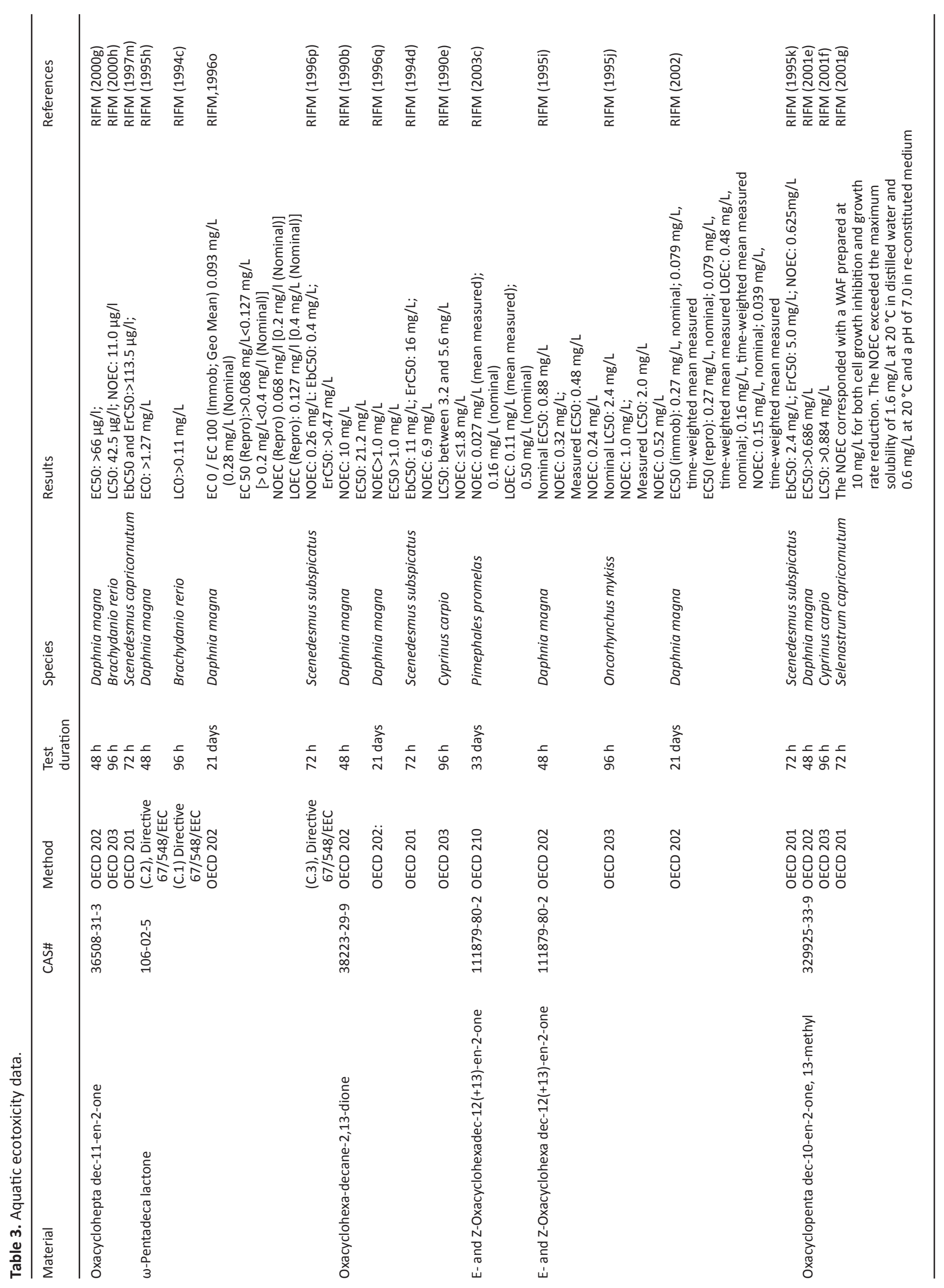




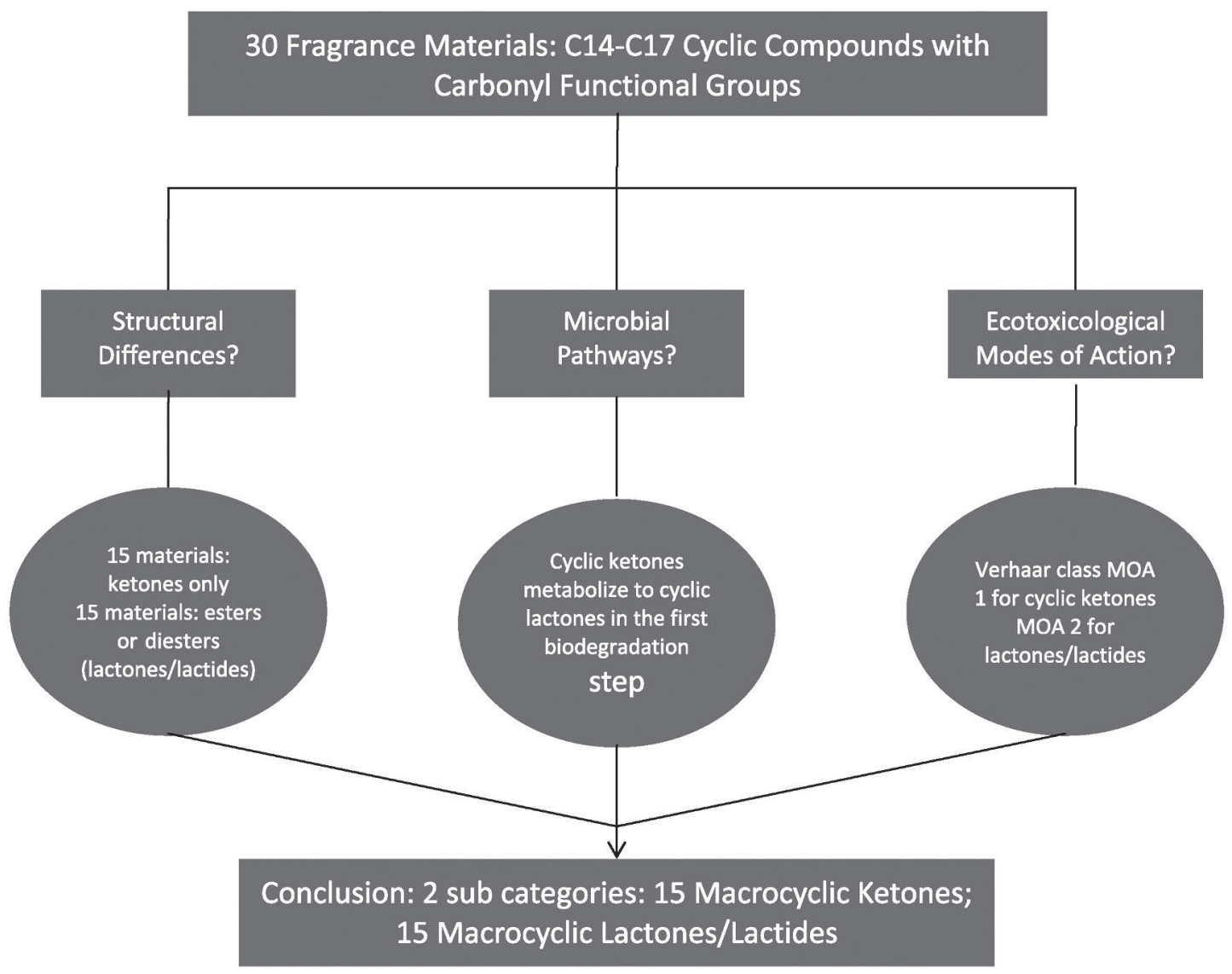

Figure 3. Decision process following categorization guidelines.

PNEC) which defines the risk quotient. When the PEC/PNEC ratio is below one, the risk from the macrocyclic group is considered to be negligible at current volumes of use and thus no adverse aquatic impacts are expected. The screening-level risk assessment answers the question: "Is there a potential for ecological risk?". When the risk quotient exceeds one, a more robust assessment of the environmental risk is warranted to attempt to quantify the magnitude and probability of those risks.

\section{Results and discussion}

Read-across plays an important role in the risk assessment that follows. Following the guidance established in Section 1 of this paper, and having supported the hypothesis that these materials can be assessed as two groups of macrocyclic compounds, it is appropriate to read across from the data presented for both biodegradation and aquatic toxicity.

\subsection{Estimation of PECs - exposure assessment}

The annual volume of use range for the macrocyclic ketones in both Europe and North America is from $<1$ (low kg quantities) to no greater than 50 metric tons in either region (resulting in the 10-100 tonne tonnage band) and for macrocyclic lactones/ lactides the volume of use range for both regions is $<1$ to no greater than 1000 metric tons in any one region; here, resulting in a $>1000$ metric tons volume of use band (IFRA, 2008).

Within the RIFM/FEMA Database there are 22 biodegradation studies available for 9 macrocyclic ketones and 28 studies for 11 macrocyclic lactones/lactides (Table 2). Following OECD Guidelines (OECD, 2006b) for determining ready biodegradation (e.g., considering the "10-day window"), macrocyclic ketones range from inherent to readily biodegradable. However, the range of biodegradation (mineralization) from these studies ranges from a low of $43 \%$ to a high of $100 \%$. In performing this assessment the quality of the data reported in the RIFM Database was evaluated. All studies followed OECD Guidelines. While data outliers are present, there was nothing present in the data reports to warrant their exclusion. Therefore, all available biodegradation were used. The low values observed are not supported by the weight of evidence from the studies (see Table 2) evaluated for any individual compound but are included in this assessment for completeness and to provide for a conservative evaluation of exposure. In applying the RIFM Framework, a conservative value of $1 \mathrm{~h}^{-1}$ is used as the biodegradation rate for these compounds. Macrocyclic lactones/lactides were largely found to be readily biodegradable with biodegradation ranging from $71 \%$ to $>100 \%$ in the available studies with a single outlier $(40 \%)$ not supported by other studies for the same compound (ethylene brassylate). In applying the RIFM Framework, while a rate of $3 \mathrm{~h}^{-1}$ is acceptable, a conservative value of $1 \mathrm{~h}^{-1}$ was applied for biodegradation in the WWTP in the exposure assessment of these compounds. Based on these data, neither the macrocyclic ketones nor the macrocyclic lactones/lactides should be considered persistent in the aquatic environment.

Based on these input parameters, and a 3:1 dilution ratio, the Framework estimates that the predicted concentration of macrocyclic ketones in river water within the mixing zone of the WWTP discharge would be range from $<0.01$ to $0.05 \mu \mathrm{g} / \mathrm{L}$ in Europe and from $<0.01$ to $0.03 \mu \mathrm{g} / \mathrm{L}$ in North America. For macrocyclic lactones/lactides, the concentration within the mixing zone would range from in Europe from $<0.01$ to 0.7 $\mu \mathrm{g} / \mathrm{L}$ and from $<0.01$ to $1.0 \mu \mathrm{g} / \mathrm{L}$ in North America. These differences between regions occur because there are different input parameters for the model for Europe and North America (e.g., per capita water use) and tonnage varies between the two regions. 


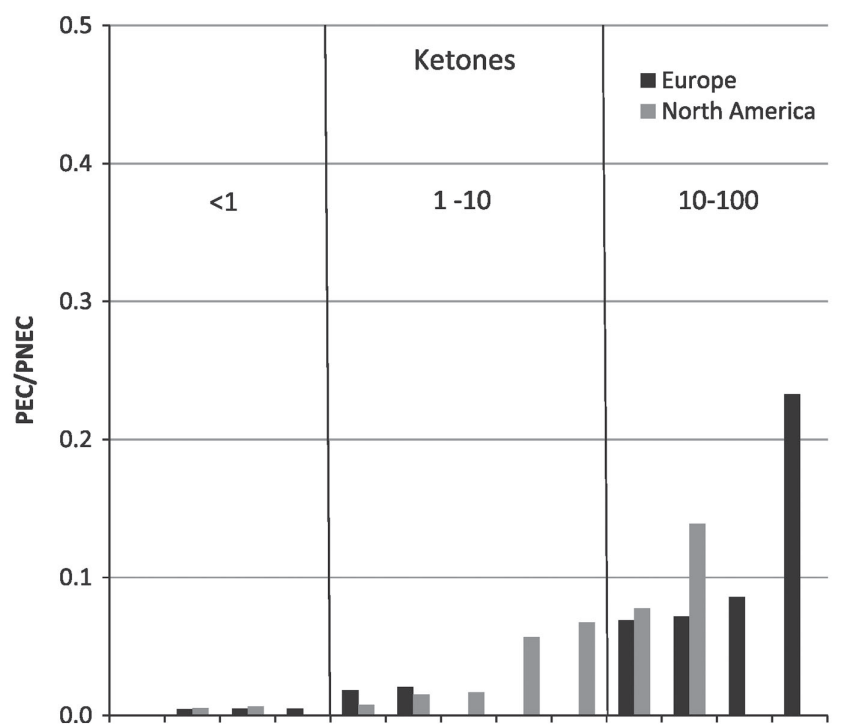

Figure 4. Risk quotients for macrocyclic ketones categorized by volume bands (metric tons). Nine out of 15 materials are presented based on their EU tonnage and 9 out of 15 based on their US tonnage. Additional materials are not included as their risk quotients were too low to be presented (0.01).

\subsection{Estimation of PNECs}

For 5 macrocyclics ketones, 3 algae inhibition studies, 4 daphnia immobilization studies, 2 fish acute lethality studies and 2 daphnia reproduction studies are available within the RIFM database. For 7 macrocyclic lactones/lactides, 7 algae inhibition studies, 7 daphnia immobilization studies, 7 fish lethality studies, 4 daphnia reproduction studies and 1 fish early life stage study are available within the RIFM Database. For the ketones, and the lactones/lactides as well, ecotoxicity studies are often difficult to perform due to the poor solubility of the materials, their volatility, and their ability to degrade. Concerns about material solubility and the usefulness of the data do not negate the conservative nature of this assessment. In performing this assessment the quality of the data reported in the RIFM Database was evaluated. All studies followed OECD Guidelines. The chronic toxicity studies, run at lower concentrations below the water solubility, provide for reliable data to be used in this group effects assessment. The acute data, while more prone to concerns about material solubility, appear to provide relatively consistent experimental values continuing to support the group effects assessment. In only one case, a Fish, Early Life Stage study of 3-methylcyclopentadecenone, was the data determined to be of sufficiently poor quality that it could not be used in this assessment (see Supplemental Information). These data are summarized in Table 3.

For the macrocyclic ketones, the lowest acute $\mathrm{EC}_{50} / \mathrm{LC}_{50}$ reported (algae, daphnia or fish) was $0.39 \mathrm{mg} / \mathrm{L}$ (D. magna immobilization study for 3-Methylcyclopentadecenone) and the lowest NOEC was $0.011 \mathrm{mg} / \mathrm{L}$ (D. magna reproduction study for 3-Methylcyclopentadecenone). Two chronic endpoints are available (algae and daphnia), therefore an assessment factor of 50, as described in Salvito et al. (2002) is applied to this NOEC. The PNEC derived for the macrocyclic ketones is 0.22 $\mu \mathrm{g} / \mathrm{L}$.

For the macrocyclic lactones/lactides, the lowest acute $\mathrm{EC}_{50} / \mathrm{LC}_{50}$ reported (algae, daphnia or fish) was $0.0425 \mathrm{mg} / \mathrm{L}$ (Danio rerio lethality study for Oxacycloheptadec-11-en-2-one). This material is reported in other studies to be very poorly soluble (mean limit of solubility reported in its D. magna immo-

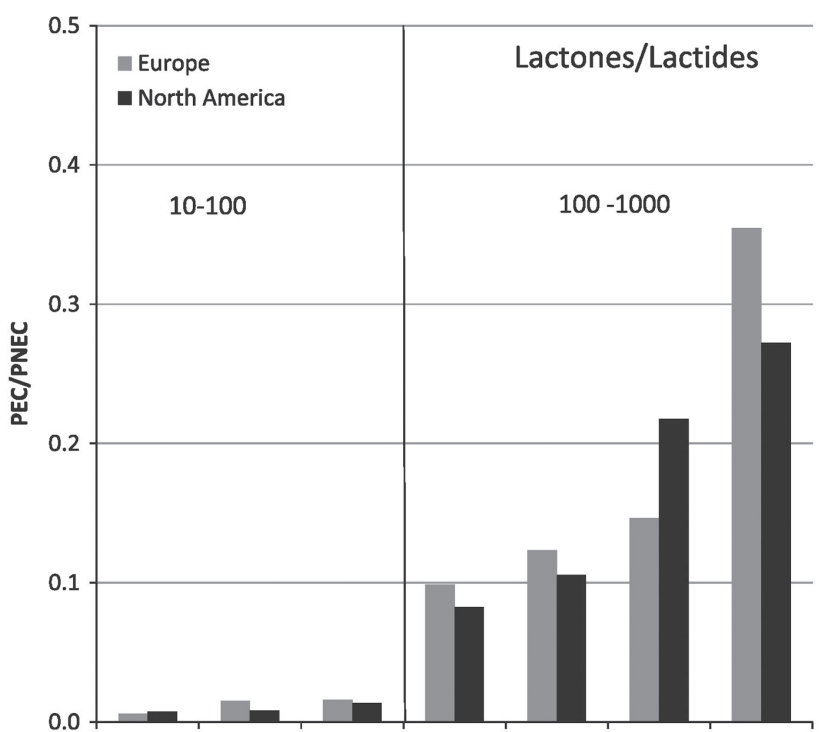

Figure 5. Risk quotients for macrocyclic lactones/lactides categorized by volume bands (metric tons). Seven out of 15 materials are presented based on their EU tonnage and 7 out of 15 based on their US tonnage. Additional materials are not included as their risk quotients were too low to be presented $(\ll 0.01)$.

bilization study is $66 \mu \mathrm{g} / \mathrm{L})$. This may explain the difference observed in acute toxicity between this material and the other lactones/lactides where the next lowest acute endpoint reported is an order of magnitude higher $\left(\mathrm{E}_{\mathrm{b}} \mathrm{C}_{50}\right.$ in an algae biomass based inhibition study for $\omega$-pentadecalactone). The lowest NOEC from a chronic toxicity study was $0.027 \mathrm{mg} / \mathrm{L}$ (fish early life stage study study for Oxacyclohexadecen-2-one). Three chronic endpoints are available (algae, daphnia, and fish), therefore an assessment factor of 10 is applied to this NOEC. The PNEC derived for the macrocyclic lactones/lactides is $2.7 \mu \mathrm{g} / \mathrm{L}$.

As with biodegradation, one rate applied to all chemicals within the subgroup, the PNEC is applied to all materials within each subgroup. Risk quotients are then calculated based on individual material PECs.

\subsection{Risk characterization}

The screening level risk quotient, PEC/PNEC ratio, for macrocyclic lactones/lactides ranges from $<0.05$ to 0.27 for the North American scenario and $<0.05$ to 0.35 for the European scenario identified in the RIFM Framework. The screening level PEC/ PNEC ratio for macrocyclic ketones ranges from $<0.05$ to 0.14 for the North American scenario and $<0.05$ to 0.23 for the European scenario identified in the RIFM Framework (Figures 4 $\& 5)$.

Since the risk quotients for all materials are less than 1.0, the potential risks of macrocyclic fragrance ingredients to aquatic biota are negligible at current use levels. The RIFM Framework, as applied, has been designed to conservatively overpredict PEC/PNEC values. This screening-level assessment only evaluated the aqueous exposure pathway. It did not consider effects to sediment organisms or exposure via bioaccumulation in food.

\section{Conclusions}

The results of a screening-level aquatic ecological risk assessment using a group approach indicates that at the current volume of use, of macrocyclic fragrance materials do not pose a 
significant risk to aquatic biota. This is primarily a function of the high degree of degradation expected in waste water treatment of macrocyclic fragrance materials resulting in efficient removal in wastewater treatment plants. Based on current volume of use, no PEC/PNEC ratio exceeds 1 for any material in any subgroup under any set of conditions identified in the RIFM Framework. The IFRA volume of use survey is revised every 4 years allowing RIFM to reassess the aquatic risk of this class of fragrance materials.

Acknowledgments - The authors gratefully acknowledge the contributions Dr. Benjamin Parkhurst made to the development of this manuscript. The authors also acknowledge the Research Institute for Fragrance Materials for their support of this project.

\section{References}

Belsito et al., in press a - D. Belsito, D. Bickers, M. Bruze, P. Calow, M. Dagli, A. D. Fryer, H. Greim, J. H. Hanifin, Y. Miyachi, J. H. Saurat, and I. G., Sipes, A toxicologic and dermatologic assessment of macrocylic ketones and derivatives when used as fragrance ingredients. Food and Chemical Toxicology, in press.

Belsito et al., in press b - D. Belsito, D. Bickers, M. Bruze, P. Calow, M. Dagli, A. D. Fryer, H. Greim, J. H. Hanifin, Y. Miyachi, J. H. Saurat, and I. G., Sipes, A toxicologic and dermatologic assessment of macrocylic lactones and lactide derivatives when used as fragrance ingredients. Food and Chemical Toxicology, in press.

Bickers et al., 2003 - D. Bickers, P. Calow, H. Greim, J. Hanifin, A. Rogers, J.H. Saurat, I. Sipes, L. Smith and H. Tagami, The safety assessment of fragrance materials. Regulatory Toxicology and Pharmacology, 37:2 (2003), pp. 218-273.

EMEA (European Medicine Agency), 2006 - EMEA (European Medicine Agency), Guideline on the Environmental Risk Assessment of Medicinal Products for Human Use CHMP/ SWP/4447/00, The European Agency for the Evaluation of Medicinal Products, London, 2006.

ECHA (European Chemical Agency), 2008a - ECHA (European Chemical Agency), Guidance on Information Requirements and Chemical Safety Assessment Part E: Risk Characterization, European Chemicals Agency, Helsinki, 2008.
ECHA (European Chemical Agency), 2008b • ECHA (European Chemical Agency), Guidance on Information Requirements and Chemical Safety Assessment Chapter R.10: Characterization of Dose [concentration]-response for Environment, European Chemicals Agency, Helsinki, 2008.

Gao et al., 2010 - J. Gao, L. Ellis and L. Wackett, The University of Minnesota Biocatalysis/Biodegradation Database: Improving public access. Nucleic Acids Research, 38 (2010), pp. D488-D491.

IFRA (International Fragrance Association), 2008 - IFRA (International Fragrance Association), Volume of Use Survey, 2008.

OECD (Organisation for Economic Cooperation and Development), 2005 • OECD (Organisation for Economic Cooperation and Development), Manual for investigation of HPV chemicals. Guidance on the Development and Use of Chemical Categories in the HPV Chemicals Programme (Chapter 3.2), 2005.

OECD (Organisation for Economic Cooperation and Development), 2006a - OECD (Organisation for Economic Cooperation and Development), OECD Guidelines for Testing of Chemicals, vol. 2. Section 2: Effects on Biotic Systems. Paris, France, 2006.

OECD (Organisation for Economic Cooperation and Development), 2006b - OECD (Organisation for Economic Cooperation and Development), OECD Guidelines for Testing of Chemicals, vol. 2. Section 3: Degradation and Accumulation. Paris, France, 2006.

Salvito et al., 2002 • D. Salvito, R. Senna, and T. Federle, A framework for prioritizing fragrance materials for aquatic risk assessment. Environmental Toxicology and Chemistry, 21 (2002), pp. 301-1308.

Thomas et al., 2008 • P. Thomas, M. Holt, P. Lemaire, I. Malcomber, D. Salvito, and R. Thompson, A weight-of-evidence (woe) approach for determining mode of Action: an ECETOC case study. IEAM, 4:3 (2008), pp. 374-375.

Vaes et al., 1998 - W.H.M. Vaes, E. Urrestarazu-Ramos, H. Verhaar, and J.L.M. Hermens, Acute toxicity of nonpolar versus polar narcosis: is there a difference?. Environmental Toxicology and Chemistry, 17 (1998), pp. 1380-1384.

Verhaar et al., 1992 • H.J.M. Verhaar, J. De Jongh, and J.L.M. Hermens, Modeling the bioconcentration of organic compounds by fish: A novel approach. Environmental Science $\mathcal{E}$ Technology, 33:22 (1992), pp. 4069-4072. 


\section{Supplemental Information}

Provided in this section is a complete set of references for the unpublished data presented in Tables 2 and 3 of the manuscript.

Other unpublished data (Table SI1) were available for sediment and terrestrial organisms, but they were not included in the main paper as this is an aquatic risk assessment for the macrocyclic fragrance ingredients. Additionally, one unpublished bioaccumulation study was also available. For completeness they are presented here.

Also of note, while one data point would not be amenable to this weight of evidence approach for chemical grouping, it should be noted that in one OECD 305 BCF study (RIFM, 1997) a macrocycliclactide (oxacyclohexadecane-2,13-dione), the measured BCF for whole fish (Onchorynchusmykiss) based on total radioactivity was $1389 \mathrm{~L} / \mathrm{kg}$ in the low dose and $2389 \mathrm{~L} / \mathrm{kg}$ in the high dose; however, significant metabolism was observed. In edible and non-edible parts of the fish analyzed, the unchanged parent compound was not observed.

Lastly provided here are figures illustrating the rationale for eliminating a Fish, Early Life Stage study from the PNEC derivation for macrocylcic ketones are also provided. In the main paper it is noted that a Fish Early Life Stage study for 3-methylcyclopentadecenone was not useful for the risk assessment of the macrocyclic ketones in developing the PNEC because there was no evident concentration response relationship. Figures SI1 and SI2 graphically present the relationships derived from this study to support this conclusion. 
Table SI1: Additional ecotoxicological data

\begin{tabular}{|c|c|c|c|c|c|c|}
\hline Material (subgroup) & CAS\# & Method & $\begin{array}{c}\text { Test } \\
\text { Duration }\end{array}$ & Species & Results & References \\
\hline \multirow{3}{*}{$\begin{array}{l}\text { 3- } \\
\text { Methylcyclopentadecen } \\
\text { one } \\
\text { (Macrocyclic Ketone) }\end{array}$} & \multirow{3}{*}{$82356-51-2$} & OECD 216 & 28 days & $\begin{array}{c}\text { Soil } \\
\text { microorganisms }\end{array}$ & NOEC $1000 \mathrm{mg} / \mathrm{Kg}$ & RIFM, $2002 \mathrm{a}$ \\
\hline & & OECD 208 & 280 days & $\begin{array}{l}\text { Oat (A. sativa) } \\
\text { Soybean (G. max) } \\
\text { Tomato (L. } \\
\text { esculentum) }\end{array}$ & $\begin{array}{l}\text { For soybean and tomato } \\
\text { for \% emergence and shoot } \\
\text { weight: } \\
\text { EC25 and EC50: >1000 } \\
\mathrm{mg} / \mathrm{Kg} \text {; NOEC } 1000 \mathrm{mg} / \mathrm{Kg} \\
\text { For Oat: EC25 (shoot } \\
\text { weight): } 180 \mathrm{mg} / \mathrm{Kg} ; \mathrm{EC} 50 \\
>1000 \mathrm{mg} / \mathrm{Kg} \\
\text { NOEC: } 110 \mathrm{mg} / \mathrm{Kg} \text { (shoot } \\
\text { weight) }\end{array}$ & RIFM, 2002 b \\
\hline & & OECD 207 & 14 days & Earthworm & $\begin{array}{l}\text { LC50: } 250 \text { mg/kg } \\
\text { NOEC: } 180 \mathrm{mg} / \mathrm{kg}\end{array}$ & RIFM, 2001a \\
\hline \multirow{3}{*}{$\begin{array}{c}\text { E- and Z- } \\
\text { Oxacyclohexadec- } \\
\text { 12(+13)-en-2-one } \\
\text { (Macrocyclic } \\
\text { Lactone/Lactide) }\end{array}$} & \multirow{3}{*}{$111879-80-2$} & OECD 207 & 14 days & $\begin{array}{c}\text { E. foetida } \\
\text { (earthworm) }\end{array}$ & $\begin{array}{l}\text { NOEC: } 1000 \mathrm{mg} / \mathrm{Kg} \\
\text { LC50: >1000 mg/Kg }\end{array}$ & RIFM,2001b \\
\hline & & OECD 218 & 28 days & L. variegatus & $\begin{array}{c}\text { Nominal EC50 (repro.): } 960 \\
\mathrm{mg} / \mathrm{kg} \\
\text { NOEC: } 320 \mathrm{mg} / \mathrm{kg} ; \\
\text { Mean Measured EC50 } \\
\text { (repro.): } 630 \mathrm{mg} / \mathrm{kg} \\
\text { NOEC: } 210 \mathrm{mg} / \mathrm{kg}\end{array}$ & RIFM,2003 \\
\hline & & OECD 208 & 30 days & $\begin{array}{c}\text { Oat (A. sativa) } \\
\text { Soybean (G. max) } \\
\text { Tomato (L. } \\
\text { esculentum) }\end{array}$ & $\begin{array}{c}\text { For all species for \% } \\
\text { emergence and shoot } \\
\text { weight: } \\
\text { EC25 and EC50: >1000 } \\
\mathrm{mg} / \mathrm{Kg} \text {; NOEC } 1000 \mathrm{mg} / \mathrm{Kg}\end{array}$ & RIFM,2002 c \\
\hline
\end{tabular}


Figure SI1

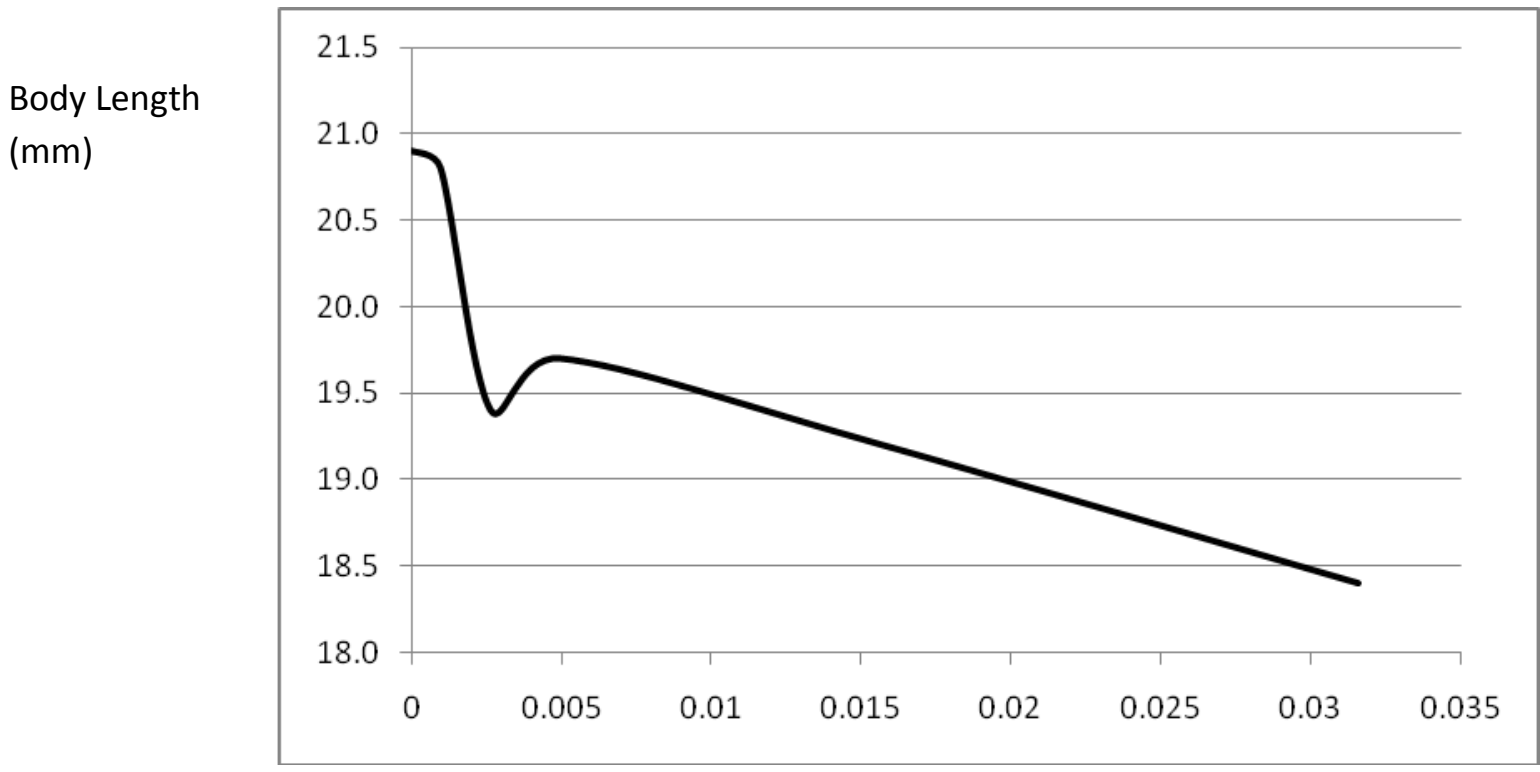

Concentration (mg/L)

Figure SI2

Body Weight (mg)

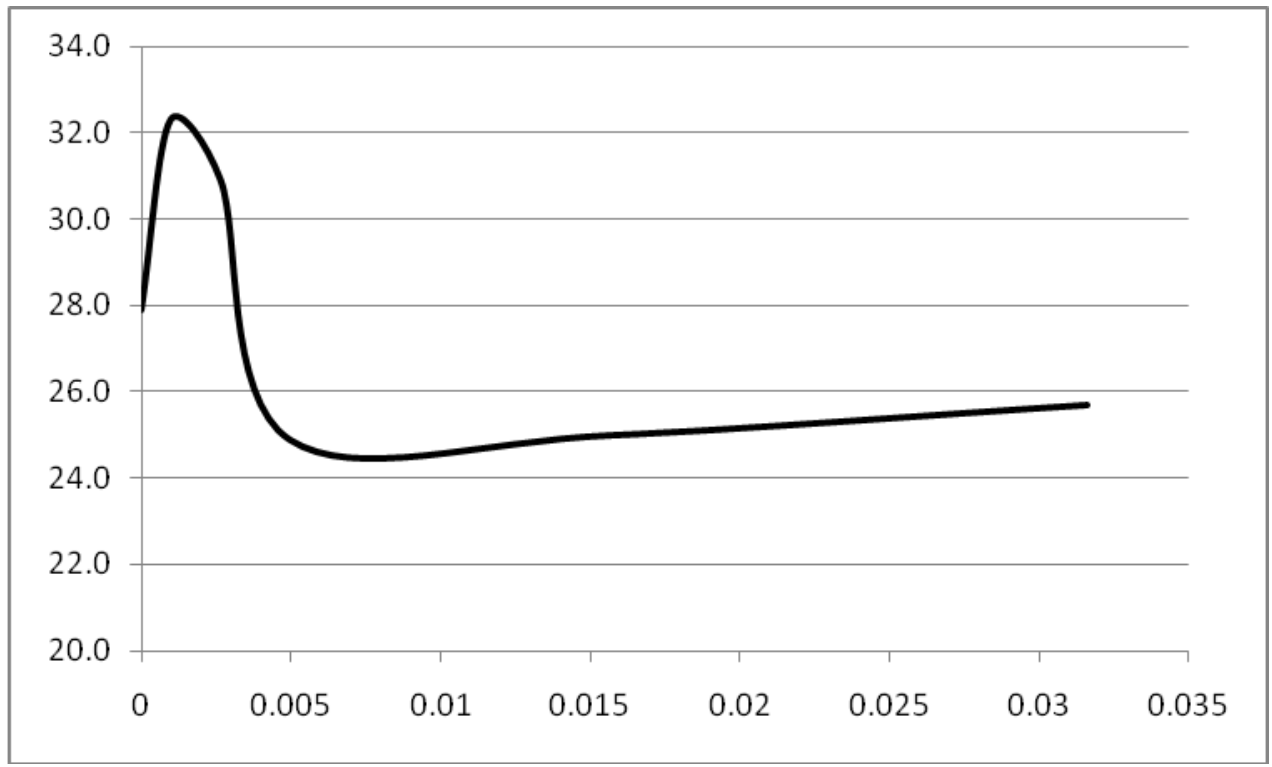

Concentration (mg/L) 


\section{References (Table SI1)}

RIFM (Research Institute for Fragrance Materials, Inc.), 1997. Accumulation and elimination of oxacyclohexadecane-2,13-dione (12-ketopentadecanolide) by Rainbow trout in a dynamic flowthrough system. Unpublished report from Symrise Inc. RIFM report number 59255 (RIFM, Woodcliff Lake, NJ USA).

RIFM (Research Institute for Fragrance Materials, Inc.), 2001a. 3-Methylcyclopentadecenone: Acute toxicity to earthworms (Eiseniafoetida). Unpublished report from Firmenich Inc. RIFM report number 43021 (RIFM, Woodcliff Lake, NJ USA).

RIFM (Research Institute for Fragrance Materials, Inc.), 2001b. Oxacyclohexadecen-2-one: Acute toxicity to earthworms (Eiseniafoetida). Unpublished report from Firmenich Inc. RIFM report number 40994 (RIFM, Woodcliff Lake, NJ USA).

RIFM (Research Institute for Fragrance Materials, Inc.), 2002a. 3-Methylcyclopentadecenone: Soil microorganisms: Nitrogen transformation test. Unpublished report from Firmenich Inc. RIFM report number 43022 (RIFM, Woodcliff Lake, NJ USA).

RIFM (Research Institute for Fragrance Materials, Inc.), 2002b. 3-Methylcyclopentadecenone: Determination of effects on seedling emergence and seedling growth of three plant species. Unpublished report from Firmenich, Inc. RIFM report number 43018 (RIFM, Woodcliff Lake, NJ USA).

RIFM (Research Institute for Fragrance Materials, Inc.), 2002c. Oxacyclohexadecen-2-one Determination of effects on seedling emergence and seedling growth of three plant species. Unpublished report from Firmenich Inc. RIFM report number 40995 (RIFM, Woodcliff Lake, NJ USA). 
RIFM (Research Institute for Fragrance Materials, Inc.), 2003. Oxacyclohexadecen-2-one: A prolonged toxicity test using spiked sediment with the oligochaete, Lumbriculusvariegatus. Unpublished report from Firmenich Inc. RIFM report number 43026 (RIFM, Woodcliff Lake, NJ USA).

\section{References (Tables 2 and 3)}

RIFM (Research Institute for Fragrance Materials, Inc.), 1990a.Assessment of the ready biodegradability of oxacyclohexadecane-2,13-dione (12-ketopentadecanolide) in the modified Sturm Test. Unpublished report from Symrise Inc. RIFM report number 59241 (RIFM, Woodcliff Lake, NJ USA).

RIFM (Research Institute for Fragrance Materials, Inc.), 1990b.48-Hour acute toxicity of oxacyclohexadecane-2,13-dione (12-ketopentadecanolide) to Daphnia magna. Unpublished report from Symrise Inc. RIFM report number 59244 (RIFM, Woodcliff Lake, NJ USA).

RIFM (Research Institute for Fragrance Materials, Inc.), 1990c. Oxacyclohexadecane-2,13-dione (12ketopentadecanolide): 96-Hour acute toxicity study in the carp. Unpublished report from Symrise Inc. RIFM report number 59245 (RIFM, Woodcliff Lake, NJ USA).

RIFM (Research Institute for Fragrance Materials, Inc.), 1993.The biodegradability of base perfume ingredients in the sealed vessel test. Unpublished report from Quest Int. RIFM report number 49593 (RIFM, Woodcliff Lake, NJ USA).

RIFM (Research Institute for Fragrance Materials, Inc.), 1994a.The biodegradability of perfume ingredients in the sealed vessel test. Unpublished report from Quest Int. RIFM report number 49702 (RIFM, Woodcliff Lake, NJ USA).

RIFM (Research Institute for Fragrance Materials, Inc.), 1994b.Ready biodegradability of oxacycloheptadec-10-ene-2-one.Unpublished report from Givaudan. RIFM report number 33472 (RIFM, Woodlicff Lake, NJ USA). 
RIFM (Research Institute for Fragrance Materials, Inc.), 1994c.Acute toxicity of w-pentadecalactone to fish. Unpublished report from Symrise Inc. RIFM report number 54971 (RIFM, Woodcliff Lake, NJ USA).

RIFM (Research Institute for Fragrance Materials, Inc.), 1995a.Assessment of ready biodegradation of 3methylcyclopentadecenone; closed bottle test. Unpublished report from Firmenich Inc. RIFM report number 36689 (RIFM, Woodcliff Lake, NJ USA).

RIFM (Research Institute for Fragrance Materials, Inc.), 1995b.Semi-continuous activated sludge (SCAS) removability test of 3-methylcyclopentadecenone.Unpublished report from Firmenich, Inc. RIFM report number 36690 (RIFM, Woodcliff Lake, NJ USA).

RIFM (Research Institute for Fragrance Materials, Inc.), 1995c.CO2 production test of oxacyclohexadecen-2-one.Unpublished report from Firmenich Inc. RIFM report number 31519 (RIFM, Woodcliff Lake, NJ USA).

RIFM (Research Institute for Fragrance Materials, Inc.), 1995d.Semi-continuous activated sludge (SCAS) removability test of oxacyclohexadecen-2-one. Unpublished report from Firmenich Inc. RIFM report number 31520 (RIFM, Woodcliff Lake, NJ USA).

RIFM (Research Institute for Fragrance Materials, Inc.), 1995e.Acute toxicty of 3methylcyclopentadecenone to Daphnia magna. Unpublished report from Firmenich Inc. RIFM report number 36685 (RIFM, Woodcliff Lake, NJ USA).

RIFM (Research Institute for Fragrance Materials, Inc.), 1995f.Acute toxicity of 3methylcyclopentadecenone in Rainbow trout (Oncorhynchusmykiss).Unpublished report from Firmenich Inc. RIFM report number 36684 (RIFM, Woodcliff Lake, NJ USA).

RIFM (Research Institute for Fragrance Materials, Inc.), 1995g.Algal inhibition test on 3methylcyclopentadecenone.Unpublished report from Firmenich Inc. RIFM report number 36686 (RIFM, Woodcliff Lake, NJ USA). 
RIFM (Research Institute for Fragrance Materials, Inc.), 1995h.Acute daphnia toxicity of wpentadecalactone. Unpublished report from Symrise Inc. RIFM report number 54972 (RIFM, Woodcliff Lake, NJ USA).

RIFM (Research Institute for Fragrance Materials, Inc.), 1995i.Acute toxicity of oxacyclohexadecen-2-one to Daphnia magna. Unpublished report from Firmenich, Inc. RIFM report number 31516 (RIFM, Woodcliff Lake, NJ USA).

RIFM (Research Institute for Fragrance Materials, Inc.), 1995j.Acute toxicity of oxacyclohexadecen-2-one to Rainbow trout (oncorhynchysmykiss). Unpublished report from Firmenich Inc. RIFM report number 31515 (RIFM, Woodcliff Lake, NJ USA).

RIFM (Research Institute for Fragrance Materials, Inc.), 1995k.Algal inhibition test of oxacyclohexadecen2-one.Unpublished report from Firmenich Inc. RIFM report number 31517 (RIFM, Woodcliff Lake, NJ USA).

RIFM (Research Institute for Fragrance Materials, Inc.), 1996a.Ready biodegradability of 5cyclohexadecen-1-ene according to the $\mathrm{CO} 2$ evolution test. Unpublished report from Soda Aromatic Company, Ltd. RIFM report number 31970 (RIFM, Woodcliff Lake NJ USA).

RIFM (Research Institute for Fragrance Materials, Inc.), 1996b.Assessment of 3methylcyclopentadecenone in the ready biodegradability manometricrespirometry test. Unpublished report from Firmenich Inc. RIFM report number 36687 (RIFM, Woodcliff Lake, NJ USA).

RIFM (Research Institute for Fragrance Materials, Inc.), 1996c.CO2 production test of 3methylcyclopentadecenone. Unpublished report form Firmenich Inc. RIFM report number 36688 (RIFM, Woodcliff Lake, NJ USA). 
RIFM (Research Institute for Fragrance Materials, Inc.), 1996d.Biodegradation of ethylene brassylate. Unpublished report from Haarmann \& Reimer Gmbh. RIFM report number 41080 (RIFM, Woodcliff, NJ USA).

RIFM (Research Institute for Fragrance Materials, Inc.), 1996e.Biodegradation of ethylene brassylate. Unpublished report from Haarmann\& Reimer Gmbh. RIFM report number 41098 (RIFM, Woodcliff, NJ USA).

RIFM (Research Institute for Fragrance Materials, Inc.), 1996f.Biodegradation of ethylene brassylate. Unpublished report from Haarmann\& Reimer Gmbh. RIFM report number 41099 (RIFM, Woodcliff Lake, NJ USA).

RIFM (Research Institute for Fragrance Materials, Inc.), 1996g. The ultimate biodegradability of base perfumes in the sealed vessel test. Unpublished report from Quest Int. RIFM report number 49435 (RIFM, Woodcliff Lake, NJ USA).

RIFM (Research Institute for Fragrance Materials, Inc.), 1996h.Ready biodegradability of omegapentadecalactone according to the $\mathrm{CO} 2$ evolution test. Unpublished report from Soda Aromatic Company Ltd. RIFM report number 31968 (RIFM, Woodcliff Lake, NJ USA).

RIFM (Research Institute for Fragrance Materials, Inc.), 1996i.Biodegradation of w-pentadecalactone. Unpublished report from Symrise Inc. RIFM report number 54974 (RIFM, Woodcliff Lake, NJ USA).

RIFM (Research Institute for Fragrance Materials, Inc.), 1996j.Assessment of ready biodegradability of oxacyclohexadecen-2-one: Manometricrespirometry test. Unpublished report from Firmenich Inc. RIFM report number 31518 (RIFM, Woodcliff Lake, NJ USA).

RIFM (Research Institute for Fragrance Materials, Inc.), 1996k.Acute toxicity study of ethylene brassylate in Daphnia. Unpublished report from Haarmann\& Reimer GmbH. RIFM report number 41074 (RIFM, Woodcliff Lake, NJ USA). 
RIFM (Research Institute for Fragrance Materials, Inc.), 1996l.Acute fish toxicity of ethylene brassylate. Unpublished report from Haarmann\& Reimer GmbH. RIFM report number 41108 (RIFM, Woodcliff Lake, NJ USA).

RIFM (Research Institute for Fragrance Materials, Inc.), 1996m.Chronic toxicity test with ethylene brassylate in Daphnia. Unpublished report from Haarmann\& Reimer GmbH. RIFM report number 49598 (RIFM, Woodcliff Lake, NJ USA).

RIFM (Research Institute for Fragrance Materials, Inc.), 1996n. Algae inhibition test with ethylene brassylate. Unpublished report from Haarmann\& Reimer GmbH. RIFM report number 49599 (RIFM, Woodcliff Lake, NJ USA).

RIFM (Research Institute for Fragrance Materials, Inc.), 1996o.omega-Pentadecalactone: Daphnia magna reproduction test. Unpublished report from Symrise Inc. RIFM report number 57687 (RIFM, Woodcliff Lake, NJ USA).

RIFM (Research Institute for Fragrance Materials, Inc.), 1996p.Acute algal toxicity of wpentadecalactone. Unpublished report from Symrise Inc. RIFM report number 54973 (RIFM, Woodcliff Lake, NJ USA).

RIFM (Research Institute for Fragrance Materials, Inc.), 1996q.Daphnia test with oxacyclohexadecane2,13-dione (12-ketopentadecanolide). Unpublished report from Symrise Inc. RIFM report number 59257 (RIFM, Woodcliff Lake, NJ USA).

RIFM (Research Institute for Fragrance Materials, Inc.), 1997a.Biodegradability on 5-cyclohexadecene-1one.Unpublished report from Takasago Int. RIFM report number 34779 (RIFM, Woodcliff Lake, NJ USA).

RIFM (Research Institute for Fragrance Materials, Inc.), 1997b.Test on the biodegradability of 5cyclohexadecen-1-one by microorganisms. Unpublished report from Takasago Int. RIFM report number 45005 (RIFM, Woodcliff Lake, NJ, USA). 
RIFM (Research Institute for Fragrance Materials, Inc.), 1997c.Ready biodegradability of 5cyclohexadecen-1-one.Unpublished report from Givaudan. RIFM report number 54304 (RIFM, Woodcliff Lake, NJ USA).

RIFM (Research Institute for Fragrance Materials, Inc.), 1997d.Assessment of the inherent biodegradability of cyclopentadecanone in a sealed vessel $\mathrm{CO} 2$ production test using acclimatised effluent from a modified semi-continuous activated sludge test. Unpublished report from Quest Int. RIFM report number 45859 (RIFM, Woodcliff Lake, NJ USA).

RIFM (Research Institute for Fragrance Materials, Inc.), 1997e.Test on biodegradability of ethylene brassylate by microorganisms. Unpublished report from Takasago Int. RIFM report number 16647 (RIFM, Woodcliff Lake, NJ USA).

RIFM (Research Institute for Fragrance Materials, Inc.), 1997f.Determination of "ready" biodegradability: Carbon dioxide (CO2) evolution test (modified sturm test) with ethylene brassylat. Unpublished report from Takasago Int. RIFM report number 32582 (RIFM, Woodcliff Lake, NJ USA).

RIFM (Research Institute for Fragrance Materials Inc.), 1997g. Determination of ready biodegradability: Carbon dioxide (CO2) evolution test (modified sturm test) with musk C-14. Unpublished report from Takasago Int. RIFM report number 32955 (RIFM, Woodcliff Lake, NJ USA).

RIFM (Research Institute for Fragrance Materials, Inc.), 1997h.Oxacycloheptadec-11-en-2-one: Evaluation of biotic degradation (modified sturm test).Unpublished report from V. ManeFils France. RIFM report number 39266 (RIFM, Woodcliff Lake, NJ USA).

RIFM (Research Institute for Fragrance Materials, Inc.), 1997i.Determination of "Ready" biodegradability: Carbon dioxide (CO2) evolution test (modified Sturm test) with 10oxahexadecanolide. Unpublished report from Takasago Int. RIFM report number 32634 (RIFM, Woodcliff Lake, NJ USA). 
RIFM (Research Institute for Fragrance Materials, Inc.), 1997j. The acute toxicity of ethylene dodecanedioate to Daphnia magna. Unpublished report from IFF Inc. RIFM report number 48565 (RIFM, Woodcliff Lake, NJ USA).

RIFM (Research Institute for Fragrance Materials, Inc.), 1997k. The acute toxicity of ethylene dodecanedioate to Rainbow trout. Unpublished report from IFF Inc. RIFM report number 48563 (RIFM, Woodcliff Lake, NJ USA).

RIFM (Research Institute for Fragrance Materials, Inc.), 1997l.The acute toxicity of ethylene dodecanedioate to the green alga Selenastrumcapricornutum. Unpublished report from IFF Inc. RIFM report number 48564 (RIFM, Woodcliff Lake, NJ USA).

RIFM (Research Institute for Fragrance Materials, Inc.), 1997m.Oxacycloheptadec-11-en-2-one: Algal inhibition test (72 hours) Selenastrumcapricornutum. Unpublished report from V. Mane Fils France. RIFM report number 39270 (RIFM, Woodcliff Lake, NJ USA).

RIFM (Research Institute for Fragrance Materials, Inc.), 1998a.Ethylene brassylate: Assessment of ready biodegradability by manometricrespirometry. Unpublished report from IFF Inc. RIFM report number 48902 (RIFM, Woodcliff Lake, NJ USA).

RIFM (Research Institute for Fragrance Materials, Inc.), 1998b.Assessment of ready biodegradability with omega-pentadecalactone (Muskalactone). Unpublished report from IFF Inc. RIFM report number 55046 (RIFM, Woodcliff Lake, NJ USA).

RIFM (Research Institute for Fragrance Materials, Inc.), 1998c.Report on biodegradability of oxacyclohexadecen-2-one by microorganisms.. Unpublished report from Firmenich Inc. RIFM report number 30369 (RIFM, Woodcliff Lake, NJ USA).

RIFM (Research Institute for Fragrance Materials, Inc.), 1999a.Ready biodegradability by the carbon dioxide evolution test method of 4-cyclopentadecen-1-one, (Z)-.Unpublished report from Firmenich Inc. RIFM report number 41993 (RIFM, Woodcliff Lake, NJ USA). 
RIFM (Research Institute for Fragrance Materials, Inc.), 1999b.4-Cyclopentadecen-1-one, (Z)-: Inherent biodegradability by the semicontinuous activated sludge (SCAS) removability test method. Unpublished report from Firmenich Inc. RIFM report number 42135 (RIFM, Woodcliff Lake, NJ USA).

RIFM (Research Institute for Fragrance Materials, Inc.), 1999c.Ready biodegradability of ethylene brassylate. Unpublished report form Givaudan. RIFM report number 51235 (RIFM, Woodcliff Lake, NJ USA).

RIFM (Research Institute for Fragrance Materials, Inc.), 1999d.Test on biodegradability of ethylene dodecanedioate by microorganisms. Unpublished report from Takasago Int. RIFM report number 40189 (RIFM, Woodcliff Lake, NJ USA).

RIFM (Research Institute for Fragrance Material, Inc.), 2000a.3-Methylcyclopentadecenone: Ready biodegradability by the carbon dioxide evolution test method. Unpublished report from Firmenich Inc. RIFM report number 36691 (RIFM, Woodcliff Lake, NJ USA).

RIFM (Research Institute for Fragrance Materials, Inc.), 2000b.3-Methylcyclopentadecenone: Inherent biodegradability by the semicontinuouse activated sludge (SCAS) removability test method. Unpublished report from Firmenich Inc. RIFM report number 42129 (RIFM, Woodcliff Lake, NJ USA).

RIFM (Research Institute for Fragrance Materials, Inc.), 2000c.Biodegradation test of 3methylcyclopentadecenone by microorganisms. Unpublished report from Firmenich Inc. RIFM report number 43023 (RIFM, Woodcliff Lake, NJ USA).

RIFM (Research Institute for Fragrance Materials, Inc.), 2000d.Ethylene dodecanedioate: Determination of ready biodegradability ( $\mathrm{CO} 2$ evolution test). Unpublished report from IFF Int. RIFM report number 47319 (RIFM, Woodcliff Lake, NJ USA). 
RIFM (Research Institute for Fragrance Materials, Inc.), 2000e.Oxacyclopentadec-10-en-2-one, 13methyl- (Nirvanolide): Abiotic degradation: Hydrolysis as a function of $\mathrm{pH}$. Unpublished report from Givaudan Inc. RIFM report number 56816 (RIFM, Woodcliff Lake, NJ USA).

RIFM (Research Institute for Fragrance Materials, Inc.), 2000f.Ready biodegradability of oxacyclopentadec-10-en-2-one, 13-methyl-.Unpublished report from Givaudan. RIFM report number 54298 (RIFM, Woodcliff Lake, NJ USA).

RIFM (Research Institute for Fragrance Materials, Inc.), 2000g.Oxacycloheptadec-11-en-2-one: Acute toxicity in Daphnia magna(48 hours). Unpublished report from V. Mane Fils France. RIFM report number 39269 (RIFM, Woodcliff Lake, NJ USA).

RIFM (Research Institute for Fragrance Materials, Inc.), 2000h.Oxacycloheptadec-11-en-2-one: Acute toxicity in freshwater fish (96 hours). Unpublished report from V. Mane Fils France. RIFM report number 39268 (RIFM, Woodcliff Lake, NJ USA).

RIFM (Research Institute for Fragrance Materials, Inc.), 2001a.Cyclohexadecanone: Ready biodegradability modified sturm test. Unpublished report form Symrise Inc. RIFM report number 55009 (RIFM, Woodcliff Lake, NJ USA).

RIFM (Research Institute for Fragrance Materials, Inc.), 2001b.Acute immobilisation test to Daphina magna strauss limit test. Unpublished report from Symrise Inc. RIFM report number 55006 (RIFM, Woodcliff Lake, NJ USA).

RIFM (Research Institute for Fragrance Materials, Inc.), 2001c.Cyclohexadecanone: Fish (zebra fish), acute toxicity test, semi-static, limit test, 96 h. Unpublished report from Symrise Inc. RIFM report number 55005 (RIFM, Woodcliff Lake, NJ USA).

RIFM (Research Institute for Fragrance Materials, Inc.), 2001d. Cyclohexadecanone: Alga, growth inhibition test. Unpublished report from Symrise Inc. RIFM report number 55007 (RIFM, Woodcliff Lake, NJ USA). 
RIFM (Research Institute for Fragrance Materials, Inc.), 2001e.Acute toxicity study in Daphnia magna with oxacyclopentadec-10-en-2-one, 13-methyl-.Unpublished report from Givaudan. RIFM report number 54297 (RIFM, Woodcliff Lake, NJ USA).

RIFM (Research Institute for Fragrance Materials, Inc.), 2001f.96-Hour acute toxicity study in carp with oxacyclopentadec-10-en-2-one, 13-methyl-.Unpublished report from Givaudan. RIFM report number 54296 (RIFM, Woodcliff Lake, NJ USA).

RIFM (Research Institute for Fragrance Materials, Inc.), 2001g.Fresh water algal growth inhibition test with water accommodated fractions of oxacyclopentadec-10-en-2-one, 13-methyl-.Unpublished report from Givaudan. RIFM report number 54295 (RIFM, Woodcliff Lake, NJ USA).

RIFM (Research Institute for Fragrance Materials, Inc.), 2002. Oxacyclohexadecen-2-one: Daphnia magna reproduction test. Unpublished report from Firmenich Inc. RIFM report number 43025 (RIFM, Woodcliff Lake, NJ USA).

RIFM (Research Institute for Fragrance Materials, Inc.), 2003a.3-Methylcyclopentadecenone: Daphnia magna reproduction test. Unpublished report from Firmenich Inc. RIFM report number 43020 (RIFM, Woodcliff Lake, NJ USA).

RIFM (Research Institute for Fragrance Materials, Inc.), 2003b.3-Methylcyclopentadecenone (muscenone Delta): Fish, early-life stage toxicity test. Unpublished report from Firmenich Inc. RIFM report number 58641 (RIFM, Woodcliff Lake, NJ USA).

RIFM (Research Institute for Fragrance Materials, Inc.), 2003c. Oxacyclohexadecen-2-one: Fish, early-life stage toxicity test. Unpublished report from Firmenich Inc. RIFM report number 43024 (RIFM, Woodcliff Lake, NJ USA).

RIFM (Research Institute for Fragrance Materials, Inc.), 2004a.Inherent biodegradability of 5cyclotetradecen-1-one, 3-methyl-, (5Z)- and 5-cyclotetradecen-1-one, 3-methyl-,(5E).Unpublished report from Givaudan. RIFM report number 54302 (RIFM, Woodcliff Lake, NJ USA). 
RIFM (Research Institute for Fragrance Materials, Inc.), 2004b. Ready biodegradability of 5cyclotetradecen-1-one, 3-methyl-, (5Z)- and 5-cyclotetradecen-1-one, 3-methyl-,(5E)-. Unspublished report from Givaudan. RIFM report number 54301 (RIFM, Woodcliff Lake, NJ USA).

RIFM (Research Institute for Fragrance Materials, Inc.), 2004c.Acute toxicity study in Daphnia magna with 5-cyclotetradecen-1-one, 3-methyl-, (5Z)- and 5-cyclotetradecen-1-one, 3-methyl-,(5E).Unpublished report from Givaudan. RIFM report number 54300 (RIFM, Woodcliff Lake, NJ USA).

RIFM (Research Institute for Fragrance Materials, Inc.), 2005. Ready biodegradability of omegapentadecalactone. Unpublished report from Givaudan. RIFM report number 51284 (RIFM, Woodcliff Lake, NJ USA).

RIFM (Research Institute for Fragrance Materials, Inc.), 2009a.Ready biodegradability of 3-methyl-1cyclopentadecanone (muscone) in a ManometricRespirometry Test. Unpublished report from Firmenich Inc. RIFM report number 58643 (RIFM, Woodcliff Lake, NJ USA).

RIFM (Research Institute for Fragrance Materials, Inc.), 2009b. ManometricRespirometry Test: Ready biodegradability of 5-cyclopentadecen-1-one, 3-methyl- (muscenonedextro) by activated sludge. Unpublished report from Firmenich Inc. RIFM report number 59565 (RIFM, Woodcliff Lake, NJ USA).

RIFM (Research Institute for Fragrance Materials, Inc.), 2009c.Alga, growth inhibition test. Effect of 5cyclopentadecen-1-one, 3-methyl- (muscenonedextro) on the growth of Pseudokirchneriellasubcapitata, static conditions. Unpublished report from Firmenich Inc. RIFM report number 59563 (RIFM, Woodcliff Lake, NJ USA).

RIFM (Research Institute for Fragrance Materials, Inc.), 2009d.Daphnia magna, reproduction test (OECD 211) semi-static exposure. Effect of 5-cyclopentadecen-1-one, 3-methyl- (muscenonedextro) on 
the reproduction of Daphnia magna. Unpublished report from Firmenich Inc. RIFM report number 59564 (RIFM, Woodcliff Lake, NJ USA). 